
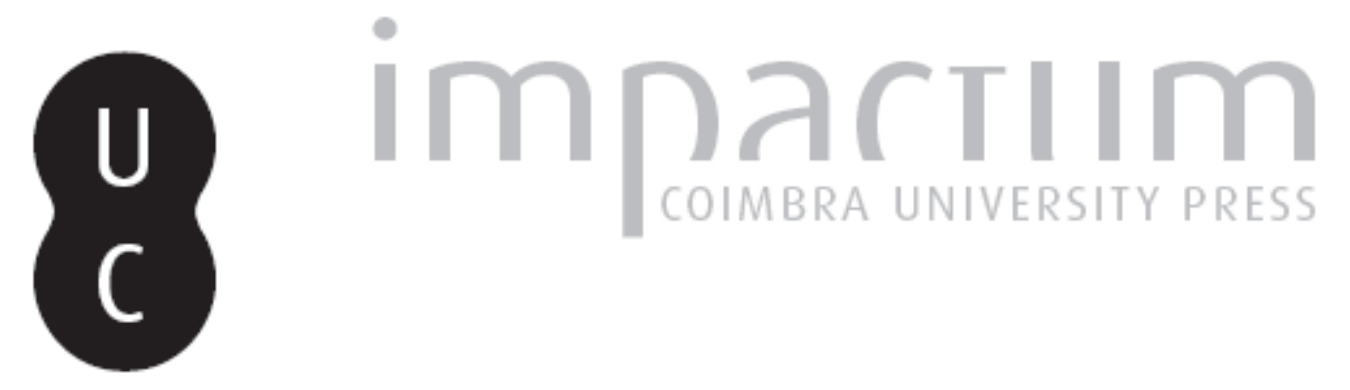

\title{
[Recensão a] João Marinho dos Santos, O Concelho de Almeida. Esboço Histórico Sociológico
}

\author{
Autor(es): $\quad$ Neto, Margarida Sobral
}

Publicado por: Centro de História da Sociedade e da Cultura

URL persistente:

URI:http://hdl.handle.net/10316.2/39697

DOI:

DOI:http://dx.doi.org/10.14195/1645-2259_7_11

Accessed : $\quad$ 26-Apr-2023 00:46:14

A navegação consulta e descarregamento dos títulos inseridos nas Bibliotecas Digitais UC Digitalis, UC Pombalina e UC Impactum, pressupõem a aceitação plena e sem reservas dos Termos e Condições de Uso destas Bibliotecas Digitais, disponíveis em https://digitalis.uc.pt/pt-pt/termos.

Conforme exposto nos referidos Termos e Condições de Uso, o descarregamento de títulos de acesso restrito requer uma licença válida de autorização devendo o utilizador aceder ao(s) documento(s) a partir de um endereço de IP da instituição detentora da supramencionada licença.

Ao utilizador é apenas permitido o descarregamento para uso pessoal, pelo que o emprego do(s) título(s) descarregado(s) para outro fim, designadamente comercial, carece de autorização do respetivo autor ou editor da obra.

Na medida em que todas as obras da UC Digitalis se encontram protegidas pelo Código do Direito de Autor e Direitos Conexos e demais legislação aplicável, toda a cópia, parcial ou total, deste documento, nos casos em que é legalmente admitida, deverá conter ou fazer-se acompanhar por este aviso.

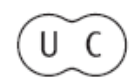




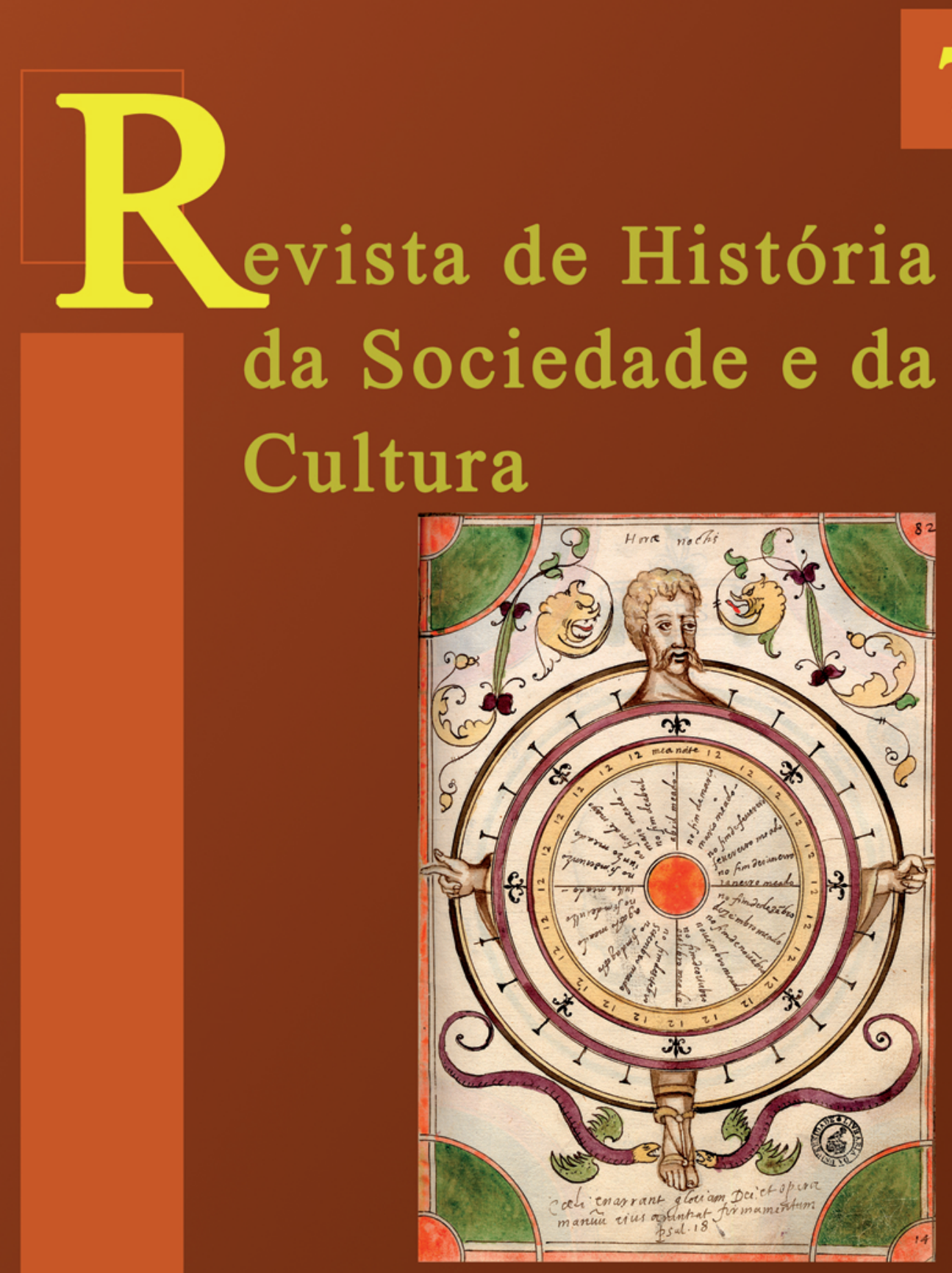

Centro de História da Sociedade e da Cultura Universidade de Coimbra

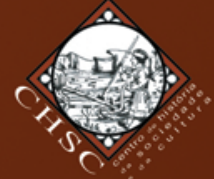


João Marinho dos Santos, O Concelho de Almeida. Esboço Histórico Sociológico. Coimbra: CHSC/Palimage Editores, 2006.

Esta obra constitui um dos frutos de um projecto que se desenvolve no âmbito do Centro de História da Sociedade e da Cultura, denominado "História da Região Centro de Portugal", e vem dar algumas respostas a problemas estruturantes desta linha de investigação: a identificação das configurações históricas dos territórios que integram a zona central do nosso país e o apuramento dos principais vectores da sua identidade.

O fio condutor deste livro é a definição dos contornos de um projecto para Riba-Côa que se consubstancie num modelo de desenvolvimento integrado e auto-sustentado, susceptível de imprimir uma dinâmica de mudança que combine tradição e inovação.

Com efeito, nesta obra encontramos, num primeiro nível, as características físicas do território, evidenciadas no clima, na geologia, na geomorfologia, na rede hidrográfica e nas paisagens.

Uma região é sempre um território apropriado pelos homens, espaço onde se teceu, ao longo do tempo, uma teia de relações humanas. Este segundo nível é-nos dado pela construção e configuração histórica da região de Riba-Côa, numa análise operada na longa duração. Ao longo do tempo, as comunidades locais organizaram-se, no sentido da satisfação dos seus interesses, tanto em matéria civil, dando origem a concelhos, como em matéria eclesiástica, formando paróquias. Neste livro, apresenta-se o caminho percorrido pelas actuais freguesias do concelho de Almeida, desde a sua organização em torno de três pólos principais - os concelhos de Almeida, Castelo Bom e Castelo Mendo - até à sua integração, no século XIX, no actual município de Almeida. O autor tem ainda a preocupação de evidenciar a forma como se organizavam internamente os lugares, apontando as diversas centralidades: o castelo ou a atalaia, a igreja matriz, o olmo (centralidade social), bem como outros espaços de vivência e coesão comunitárias.

Um terceiro nível de análise reporta-se à identificação e aproveitamento dos recursos naturais, desde os minerais e os hidrográficos aos relativos ao manto florestal, à flora e à fauna. A vida económica ribacodense estruturou-se em torno de três sectores principais: a agricultura cerealífera, a floresta e a pecuária. No contexto das actividades económicas referem-se ainda 
as artesanais, ligadas ao aproveitamento de matérias-primas autóctones, e o comércio transfronteiriço gerador de importantes fluxos económicos e de densas memórias locais. Por sua vez, o quadro económico actual é apresentado a partir da informação estatística disponibilizada pelo censo de 2001 em que se identifica como principais sectores empregadores: o comércio a retalho e por grosso, a pequena industria transformadora, a indústria alimentar e a construção civil.

Finalmente, João Marinho dos Santos debruça-se sobre o património material e imaterial. Os homens e as mulheres que habitaram a região de Riba-Côa construíram e tiveram a oportunidade de desfrutar de um património de índole diversa. Deste património é-nos dada uma visão muito abrangente, salientando-se a arquitectura militar (castelos e atalaias), a religiosa (igrejas, mas também as alminhas e os cruzeiros) e a civil (os pelourinhos, as casas rurais, e outras marcas identificadoras da paisagem, como é o caso dos típicos muros de granito que dividem as parcelas de terra). Uma parte significativa destes bens culturais existe ainda, constituindo este livro um forte apelo para a necessidade da sua preservação e recuperação.

Mas para além das pedras que mostram o rosto enrugado de uma história muito longa, há outro património mais volátil e que envolve maior risco de desaparecimento, dado que muitas vezes só permanece na memória oral. Esta memória é constituída por formas de sociabilidade profana (ciclos e rituais agrários) e religiosa (festas) bem como por diversas manifestações de relações interpessoais que fazem a coesão das comunidades. Num registo que se aproxima da antropologia cultural e da etnografia, João Marinho dos Santos apresenta, nesta obra, um contributo fundamental para a identificação das memórias culturais locais, um dos traços da identidade ribacodense.

Como já referi, a análise neste livro é feita na longa duração (tendo como momentos fortes a Idade Média, o século XVIII (memórias paroquiais), e o século XIX (período em que se registou o impacto da regeneração no território, sobretudo ao nível do ensino, das medidas de salubridade e das vias de comunicação, oportunidade para demonstrar o esforço feito pelas autoridades locais oitocentistas no sentido de promover o progresso).

A caracterização do concelho de Almeida é, no entanto, mais fina e estatisticamente mais alicerçada na actualidade. Com efeito, a informação disponibilizada pelos censos, em particular pelo de 2001, permitiu ao Autor, 
a partir de uma multiplicidade de indicadores, desde os demográficos àqueles que permitem aferir da qualidade de vida - habitação, cuidados de saúde, consumo de luz eléctrica, níveis de escolaridade - identificar os principais problemas do concelho de Almeida, nos inícios do século XXI.

Um dos objectivos do Doutor João Marinho dos Santos ao publicar esta obra foi dar a conhecer a região de Riba-Côa e o concelho de Almeida, conferindo-lhe uma identidade historicamente alicerçada. Mas não ficou por aqui. Neste livro, apresenta-se uma aturada reflexão sobre as forças e fraquezas de Riba-Côa e propõem-se ideias para o Futuro. Tanto a reflexão como as propostas que perpassam por este livro alicerçam-se em alguns pressupostos: um deles é o que diz respeita ao tipo de desenvolvimento. O modelo proposto tem como matriz teórica os novos modelos de desenvolvimento que implicam uma visão integrada da vida das sociedades (por oposição aos modelos das sociedades industriais estruturados a partir de uma visão economicista, muitas vezes desrespeitadora do meio ambiente e humano). Estes paradigmas combinam ainda tradição e inovação, contrariando frontalmente a identificação de passado com atraso. Este paradigma tem, igualmente, subjacente, fortes preocupações humanistas expressas na preocupação com a qualidade de vida das pessoas, incluindo as mais idosas e desprotegidas.

Alicerçado numa espessura histórica e numa reflexão atenta sobre os problemas da actualidade, e passando da teoriaà prática, João Marinho dos Santos apresenta, nesta obra e na sequência de publicações anteriores, um contributo para a execução de um Projecto Integrado de Desenvolvimento de Riba-Côa constituído por um conjunto de sugestões concretas para a criação de um Eco-museu, denominado "Fortificações e casas Rurais Típicas de Riba-Côa", iniciativa que visa a valorização e fruição do património natural e histórico-cultural. A prossecução deste projecto levaria, na opinião do autor, à dinamização de um conjunto de actividades económicas susceptíveis de criação de fontes de riqueza local, propiciadoras de uma melhoria da qualidade de vida dos habitantes do concelho de Almeida. Entre essas actividades destacam-se as orientadas para a criação de estruturas propícias ao acolhimento de um turismo "intimista", que procura a fruição de espaços de comunhão intensa com o meio ambiente e com as vivências culturais dos lugares. 